\title{
Molly Ladd-Taylor, Fixing the Poor: Eugenic Sterilization and Child Welfare in the Twentieth Century (Baltimore, MD: Johns Hopkins University Press, 2017). 304 pp. Cloth \$54.95, Paperback \$29.95.
}

The history of institutional pressures regarding who should parent in the United States follows two tracks, both taking shape around the time of the First World War. The more recognized trajectory lies in a eugenics-inspired vision of who deserves to reproduce, which stratified motherhood into the deserving and undeserving. The less known trajectory, which also leads to twentieth-century practices of sterilization, traces the history of coercive pressures put on women receiving welfare and includes the unacknowledged sterilization of almost a quarter of new Indigenous mothers by the Indian Health Service and the termination of parental rights for women who were imprisoned. This second trajectory demands a more nuanced examination of the social welfare landscape created at the same time that American eugenics flourished. Molly Ladd-Taylor's new work, Fixing the Poor: Eugenic Sterilization and Child Welfare in the Twentieth Century unpacks the intricate connections between these two paths, helping us see the need to account for both in order to understand where we are now. Fixing the Poor demonstrates an amazing command of the current scholarship in childhood studies, the history of eugenics and genetics, reproductive justice, the history of disability, and the history of welfare along with legal, administrative, and institutional history.

Ladd-Taylor focuses her narrative on the interrelationship between legal and administrative bureaucracies in Minnesota over the course of the twentieth century, allowing her to interpret a tangle of policies and practices and, in doing so, move our understanding of sterilization beyond a familiar eugenic narrative into the realms of welfare policy, children's protective services, and family planning. As she points out, Minnesota was neither the first state to propose sterilization (Indiana holds this honour), nor the state with the most sterilizations (California). It was neither the state that produced the Supreme Court case that legitimated sterilization (Virginia) nor the one with the most aggressive policies (North Carolina). Like Vermont, it was a state with a theoretically voluntary sterilization policy. Books have been written about all of these states, but, as Ladd-Taylor suggests, we learn a great deal more about how to understand the spectrum of sterilization programs when we consider Minnesota. She chose Minnesota because it represents a middle ground and, as such, allows for a scholarly examination of exactly how broad sterilization policies were developed and implemented.

Minnesota was the first state in the country to adopt a Children's Code, designed to destigmatize illegitimacy, modernize adoption, and shift the state away 
from the automatic institutionalization of vulnerable children in orphanages. The 1917 Children's Code also afforded the state legal power over what were called the "defective, delinquent and dependent classes." As Ladd-Taylor notes, the context of the Children's Code offers a unique perspective for understanding sterilization and ties it to the development of social welfare policy. Putting the development of the "idealized" child, or as Viviana Zelizer called it "the Priceless Child," alongside a construction of what Minnesota eugenicists like Charles Taylor Dight called the "Feebleminded Menace" speaks to the initial rationale for state-sponsored sterilization. In Ladd-Taylor's hands, this confluence informs a much more complex narrative of sterilization. The eugenics narrative, which linked the practice of sterilization to the perceived problem of the disabled, leading to the Buck v. Bell Supreme Court decision of 1927, is reframed in terms of the much less explored social welfare landscape which informed the passage of Minnesota's sterilization law in 1925.

Even the local eugenicist Charles Dight was an anomaly in his own state. Described as a “one-man show" (77), Ladd-Taylor's careful work allows us to understand how sterilization in Minnesota developed under even "the best case scenario" within a "broad set of social welfare policies that aimed to solve the problems of poverty, sex, and single motherhood by 'fixing' the poor" (2). Using the institutional and medical records of Minnesota's Faribault School, along with those of the Sauk Center Minnesota Home for Girls, Ladd-Taylor moves beyond the narratives that discuss state development of eugenics-focused sterilization to explore how programs were developed and what the intention was behind them. She finds that even as well-intentioned administrators, like the long-serving Director of the Faribault School, Mildred Thomson, resisted population-based rationales for sterilization to consider the options of people who were subjected to surgical operations, they developed an administrative and legal structure that endures. Through careful attention to court cases, newspaper accounts, and personal records by people identified as "feebleminded," she develops an analysis of the part of a three-step process of commitment, institutionalization, and eventual sterilization, often offered as the "price of freedom" from the state institution. This process, influenced by state economic concerns that fit with the well-intentioned visions of reformers, allowed the continuation of coerced sterilization long after eugenics had been debunked. Ladd-Taylor's insistence on following the trail of records through shifting definitions of independence and poverty during the Depression and post-World War II eras helps us to understand the malleability of these ideas. Even as the 1960s and 1970s brought rights-based discussions of poverty and disability, framing the discussion as a move from "fixing the poor" to "fixing the system," there remained important connections to current situations. In a state with requirements for "voluntary" consent and within a child welfare system that set the standard for the country, this interrogation allows us to understand the impact of similar legal and administrative realities of our moment, one where the same kind of economic and 
biased constraints continue to affect how we understand poverty.

The connection between eugenics and welfare policy has received more scholarly interest of late, most notably in scholarship about Scandinavia, but examining its history in North America helps us to understand how supposedly good intentions must be carefully considered. As the reproductive justice movement warns us, the vast majority of sterilizations occurred in the United States not during the era when eugenics was widely accepted but fifty years later, during the era when the War on Poverty occupied our reform landscape. Indeed, the landmark court case which helped to call attention to imposed sterilization was the 1973 Relf $v$. Weinberger. This book helps us understand this much more contemporary context by mapping the complex trajectories toward that decision.

Historians are often reluctant to draw direct connections between contemporary policy practices and what we can learn from the past. This has the unfortunate effect of yielding policy assessment to political scientists or anthropologists who are happy to help us to unpack what we can learn from the past. Molly Ladd-Taylor's commanding text offers an unflinching assessment of exactly how paying attention to the legal and administrative structures of the past can help us reimagine how to assess our current endeavours. It is a work we all need to read.

Laura Lovett 